\title{
SETENTA ANOS DA AGB: AS TRANSFORMAÇÕES DO ESPAÇO E A GEOGRAFIA DO SÉCULO XXI ${ }^{1}$ OCULTAÇÃO DO ESPAÇO E DA GEOGRAFIA
}

\author{
Arlete Moysés Rodrigues*
}

\section{RESUMO:}

O texto debate alterações da divisão territorial do trabalho, da produção e reprodução do espaço, das relações de trabalho, do avanço técnico-científico, desde a criação da AGB em 1934. Mostra um aparente paradoxo entre a importância do espaço para o sucesso do modo de produção capitalista e a forma como se tenta ocultar sua importância. Destaca que é a importância do objeto de estudo dos geógrafos torna difícil sua inserção no emaranhado das ciências. Debate os deslocamentos discursivos com o predomínio do neoliberalismo, das corporações multinacionais o que implica, para os geógrafos, vencer muitos desafios para desvendar o que se oculta nos discursos dominantes no século XXI.

\section{PALAVRAS-CHAVE:}

Geografia, Território, Relações de Trabalho, Produção do Espaço

\section{ABSTRACT:}

This text debates alterations in work territorial division, production and reproduction of space, work relations and technician-scientific advance, since the creation of AGB in 1934 . It shows an apparent paradox between the importance of space for capitalist way of production and the way it's tried to occult its importance. It detaches that it is the importance of the object of study of the geographers that turns difficult its insertion in the entanglement of sciences. It debates the discursive displacements with the predominance of neoliberalism, of multinational corporations what implies, for geographers, to overcome many challenges to unmask what it is occulted by dominant speeches in 21st century.

\section{KEY WORDS:}

Geography, Territory, Work Relations, Space production.

\section{I - Apresentação}

Farei algumas ponderações que refletem algumas inquietações e reflexões sobre as transformações no espaço entre 1934 e 2004 e as perspectivas para a Geografia no Século XXI, tendo como pressupostos:

Que a ciência geográfica é menos poderosa do que o Espaço, que é seu objeto de análise, pois o espaço é socialmente produzido, consumido, reproduzido, alterado, redimensionado.
Que o poder de intervenção ou atuação no espaço depende da apropriação e propriedade (terra, capital, meios e força de produção) que garantem o poder em seus vários matizes.

Que o poder do espaço e da geografia que o analisa são demonstráveis pela tentativa de ocultar a importância do espaço e dos geógrafos.

Que a exclusão dos trabalhadores do processo de produção, a pobreza da maioria da 
população, os problemas sócio-ambientais, a dilapidação dos elementos da natureza, são resultados do sucesso do modo de produção capitalista e não de seu fracasso.

\section{II - Algumas idéias sobre transformações do Espaço no período dos setenta anos da AGB considerando:}

-as alterações na divisão territorial do trabalho que desloca a centralidade do poder econômico, político e financeiro dos Estados Nação para as corporações multinacionais;

-que as corporações multinacionais dominam o avanço tecnológico e as suas formas de utilização, para o bem e para o mal, ou seja para a medicina e para a guerra;

-que o avanço técnico, no atual momento histórico denominado de tecnosfera acelera a compreensão do tempo/espaço, no sentido utilizado por Harvey (1992), tornando trabalhadores desnecessários para o capital, intensifica o esgotamento das reservas naturais, a poluição do ar, da água, do solo. O avanço técnico integra a produção destrutiva;

- que há continuidade da concentração da riqueza, centrada no capital financeiro que tem como medida as contas nacionais e internacionais e no capital volátil;

- que há um aumento da pobreza, da miséria em todos os lugares, vinculado ao sucesso do modo de produção capitalista;

- a intensificação da violência em geral e das guerras que pressupõem domínio e poder.

Em relação a estes aspectos pontuamos, simplificadamente:

Que em 1934, quando da criação da Associação dos Geógrafos Brasileiros AGB predominava a população rural e as atividades agrícolas enquanto que no final do século $X X$ predomina a população urbana, concentrada sobretudo nas regiões metropolitanas, nas capitais de estados e aglomerados urbanos;
Que houve vários desmembramentos das unidades da federação com a criação de alguns estados e de muitos municípios, em especial na década de 80 e 90 do século XX;

As cidades, sedes dos mais de 5.600 municípios são muito diversas em relação à quantidade de população urbana, às atividades exercidas, à forma e conteúdo dos limites territoriais urbanos, às formas de sobrevivência, etc. Mais de $80 \%$ da população urbana está localizada em apenas 1.000 municípios;

O padrão de urbanização excludente, calcado na busca do lucro, da renda e dos juros, ou seja na reprodução do capital, reproduz no espaço a segregação social;

A terra rural continua concentrada em poucos proprietários. Há grande número de propriedades improdutivas contrastando com o número dos que não tem terra para plantar. A agricultura, em especial a de exportação, está subordinada à indústria de pesticidas, de máquinas e tratores e suas variantes, de pesticidas e insumos;

A produção do espaço é social o que não quer dizer que seus frutos sejam socializados. Em todo o território - campo e cidade - as condições de acesso da maioria da população aos produtos, bens e serviços, são extremamente precárias com diferentes dimensões e características;

A indústria, nas primeiras décadas do século $X X$, era tida como promotora do desenvolvimento, como demonstram os indicadores utilizados na época. No final do século o desenvolvimento embora alicerçado nas indústrias ganha outras palavras para demonstrar sua importância e a possibilidade de continuidade do progresso: o desenvolvimento sustentável;

As contas nacionais e a tecnologia são as medidas utilizadas para avaliar o desenvolvimento. Os indicadores alteram-se da economia para o financeiro. Da produção para as contas, da produção para o consumo, para o mercado. 
Setenta anos da AGB: As transformações do espaço e a Geografia do Século XXI,

Todas as atividades econômicas estão conectadas ao uso de novos padrões tecnológicos. A tecnosfera, permite informação imediata do que acontece do mundo e assim o capital volátil é a marca da era atual. A tecnosfera ou tecnociência indica uma mutação das formas de produzir. Como diz Laymert Garcia dos Santos:

" A sociedade passa por um processo de tecnologização com reordenação e reprogramação do processo de trabalho em todos os setores, tornada possível pela digitalização crescente dos circuitos de produção, circulação consumo, ao qual veio associar-se a recombinação da vida, tornada possível pela decifração do código genético e os avanços da bioctenologia..." (Santos, 2003:120)

Ganha importância o capital financeiro, o mercado, a competitividade como alavancas do progresso. As contas são utilizadas para tratar de qualquer tema e são sempre virtuais em relação ao lastro da produção. Diariamente somos informados, pela rede televisiva, sobre a cotação do dólar, índice Bovespa, Naschua, Nasdaque, risco Brasil, etc. e a realidade da produção, das condições de vida aparecem apenas como problemas.

$\mathrm{Na}$ década de 40 século $X X$ regulamentou-se com a CLT e o salário mínimo, as relações de trabalho para incentivar a industrialização. Já a década de 90 do mesmo século, marca o seu oposto, com a desregulamentação ou flexibilização de trabalho, mostrando uma outra face da produção em geral e da produção do espaço. Altera-se o discurso mas a essência é a mesma. Afirma-se que as normas de regulamentação do trabalho são ultrapassadas, impedem o desenvolvimento. Porém são mantidos os mesmos critérios, os mesmos itens para calcular o salário mínimo, inseridos na nova ótica das contas da previdência.

O espaço, na década de 30 e seguintes, era tido como suporte das atividades como se estivesse desvinculado da sociedade que o produz. Para atingir a meta do desenvolvimento verificavam-se as potencialidades dos recursos naturais como ferro, carvão, petróleo, água para geração de energia, regulamenta-se o trabalho, etc.

Uma questão para a Geografia no século XXI é analisar nos discursos oficiais de que forma o espaço ainda está oculto e qual a sua importância real.

O Estado tinha centralidade nos discursos mas desde que o neoliberalismo tornou-se hegemônico, parece perder importância. Contudo é o Estado que regula e regulamenta as relações nacionais e internacionais. Ao Estado se dirigem os movimentos da sociedade buscando alterar a dinâmica da acumulação desigual e combinada.

As formas pelas quais os detentores do poder que também dominam as técnicas apropriam-se da biodiversidade e da sóciodiversidade são ainda pouco desvendadas.

O poder relacionado ao avanço técnico da biotecnologia e a biodiversidade lançam para o futuro a "biodiversidade" guardando-a em bancos de patentes, fora do lugar onde as espécies se desenvolvem e do conhecimento histórico de comunidades.

Desloca-se o território para os laboratórios? O território parece ficar vazio de conteúdo, tudo está catalogado e guardado em bancos de germoplasma e de patentes intelectuais.

Há novas roupagens para velhas questões: o trabalho, a produção, a qualidade de vida, os padrões de urbanização, a apropriação e a propriedade no campo, o desenvolvimento sustentável, a tecnosfera, etc. são, contudo, formas de continuar a ocultar as relações sociais.

Utilizo ocultar as relações sociais com o mesmo significado do fetiche da mercadoria na concepção marxista. O fetiche é a forma de descrever o processo social com inversão da realidade social mostrando apenas uma parte da realidade. Como diz Marilena Chauí, "no modo 
de produção capitalista, em lugar das relações sociais serem relações entre os sujeitos mediadas pelas coisas, elas são relações entre as coisas mediadas pelos sujeitos" (Chauí, 2004)

Dar visibilidade as relações sociais é desvendar, tirar a cortiça de fumaça que impede a análise sobre a importância do espaço.

Se as relações sociais, o espaço não fossem mais poderosos do que as ciências que os analisam porque o discurso dominante procuraria ocultá-los? Este é um dos significados do pressuposto que afirmei no início, de que o espaço é mais poderoso que a Geografia e que as chamadas crises decorrem do sucesso do modo de produção e não do seu fracasso.

\section{III- Ênfase nos Avanços Tecnológicos e na Problemática Ambiental}

Retomando a questão do avanço da tecnologia que favorece, também, ocultar o espaço, destaco ainda que:

Os avanços tecnológicos permitem "liberação" de trabalhadores (substituídos por máquinas - no campo e na cidade) com aumento do desemprego especializado, do desemprego estrutural, modifica a formas de exploração e espoliação do trabalhador e provoca rápidas transformações no espaço.

As máquinas e ferramentas tornam-se rapidamente obsoletas incentivando 0 "consumo" de determinados produtos sempre revestidos de "novo": os novos produtos, as novas tecnologias, as novas embalagens, novos desenhos, etc. tornando os "consumidores" cativos do novo que o são apenas na aparência.

Os avanços tecnológicos aceleram o uso dos elementos da natureza e a escala da dilapidação com alterações substanciais no espaço ganha visibilidade.

A visibilidade da importância dos elementos da natureza provocada pela produção destrutiva, cria, recria uma nova característica da idealização da natureza, num mito de eterno retorno, como destaca Chauí (Chauí, 2000).

A natureza, após o relatório da ONU "Nosso Futuro Comum", é divulgada como um patrimônio da humanidade. Os países tropicais que detêm a maior biomassa do planeta são considerados "reservas" da humanidade mas como continuam sendo tidos "incapazes" de cuidar de seus recursos, precisam do monitoramento e domínio dos países ricos que forneceriam a tecnologia e os recursos financeiros.

Atribuir-se à natureza o qualificativo de "bem comum", de patrimônio da humanidade, sem que as formas de apropriação e propriedade sejam alteradas é uma maneira de escamotear sua importância para a reprodução da vida e também ocultar quem são os agentes da dilapidação.

Um dos nossos desafios é compreender as formas de produção do espaço no século XXI, relacionadas ao meio-técnico científico informacional, no dizer de Milton Santos (Santos,1996) ou com os motores que revolucionam a história e o espaço no dizer de Paul Virilio (Virilio,1996). Não se trata de analisar a técnica em si mas de politizar as novas tecnologias para compreender a Geografia do Século XXI. Politizar a tecnofera implica em analisar a complexidade.

Os motores (vapor, explosão, turbinas, foguetes, computador) e suas poderosas máquinas - tratores, ônibus, caminhões, automóveis, o avião, modificam as formas de produção do urbano e do rural, impõe um novo ritmo, introduzem novos elementos para a circulação de pessoas e mercadorias em estradas, avenidas, ruas, aeroportos, estações espaciais, infovias, etc. Impõem um padrão urbano e rural para dar fluxo às novas mercadorias, para guardá-las em casa ou fora dela, em garagens, desenvolve indústrias consideradas baluartes do progresso 
Setenta anos da AGB: As transformações do espaço e a Geografia do Século XXI,

Estes motores e suas poderosas máquinas produzem também acessórios cada vez mais sofisticados ou "novos". Os automóveis, por exemplo, fabricados inicialmente para durar muitos anos hoje tornam-se rapidamente fora de moda, não só porque estragam mas também pelos novos acessórios e pela mudança de aparência. Diretamente todas máquinas e seus motores e outros produtos inserem-se na produção destrutiva: ferro, carvão, aço, petróleo, vidro, materiais elétricos, provocam aumento de poluição do ar, da água e do solo. Os aviões provocam, em particular, onde se instalam problemas de saúde para os moradores, na zona de cone de ruídos, modifica o uso do solo em vastas áreas dos chamados complexos aeroportuários. Os congestionamentos aceleram o stress (doença moderna), segregação social e espacial para os que não tem acesso e para os que são expulsos para a construção do "novo" - edifícios, estradas, avenidas, aeroportos, usinas hidroelétricas, etc.

Este processo interfere diretamente no preço do solo urbano e na terra rural. Direta e indiretamente aumentam a área de impermeabilização do solo urbano. Enterramse os rios (em geral já poluídos) e ocupam-se os fundos de vales com amplas avenidas para que o fluxo de veículos tenha vazão. Indiretamente, dada a forma de ocupação urbana e a impermeabilização, aumentam as enchentes ou as mesmas são deslocadas para a montante de onde os rios foram canalizados.

A relação dos motores e máquinas é observável nas edificações urbanas. Witold Rybcznski ao analisar a urbanização dos Estados Unidos mostra como os arranha céus só foram construídos após a descoberta do telefone. (Rybczynski 1996) Podemos acrescentar os elevadores para automóveis, as câmaras de tv e as gravações em vídeo tape para a segurança dos que moram ou trabalham nos edifícios. A ocupação do solo provoca aumento da ilha de calor nas áreas de maior concentração de edifícios e de circulação de veículos, altera as áreas de pluviosidade como se observa em São Paulo (as chuvas de convecção estão mais concentradas na área urbana e não mais nas áreas de mananciais hídricos) provocando indiretamente maiores problemas para o abastecimento de água. Para diminuir a temperatura no interior dos edifícios conta-se com o ar condicionado, que consome energia, aumenta a ilha de calor, provoca doenças respiratórias pelos ácaros e lança CFC na atmosfera contribuindo para o aumento do buraco na camada de ozônio.

Ao mesmo tempo, por exemplo, o automóvel dá status à quem o possui. Produzse ídolos de corridas automobilísticas, que para ocorrerem, também modificam o espaço com a construção dos autódromos destinados à competição entre as marcas de motores ou seja entre as corporações multinacionais.

A produção do espaço e o uso de várias máquinas e motores da história necessitam de iluminação e de energia. Para a geração de energia os impactos são variáveis. No Brasil com o predomínio da hidroeletricidade, são alagadas extensas áreas agricultáveis. Para este fim desloca-se pessoas como se fossem objetos para que o progresso seja atingido. È o potencial da geração de energia que interessa é assim os seres humanos são desqualificados para atingir-se o progresso. O movimento dos atingidos pelas barragens mostram a organização da sociedade civil e as lutas que são travadas para obter-se um mínimo de compensação pelos prejuízos diretos na reprodução da vida. Cabe acrescentar que as grandes represas, além dos problemas já conhecidos, alteram a dinâmica das chuvas e da distribuição de águas.

A água, elemento vital, torna-se cada vez mais escassa e cara. Um desafio no século XXI é pensar nesta questão. A abundância da água potável foi uma grande falácia.

Enfrentar a escassez é um problema real que não pode ser escamoteado com falsas questões, como por exemplo, culpar apenas os que ocupam as áreas de reservas de mananciais hídricos. Com relação à água, além de analisar 
e verificar possibilidades de abastecimento é preciso estar atendo para novas formas de apropriação do território que implicam na apropriação deste elemento vital por corporações multinacionais. Há denuncias de que os Estados Unidos procuram formas de explorar o aqüífero Guarani considerado uma das grandes fontes de água potável da América Latina.

Como diz Noam Chomsky as guerras no século XXI dar-se-ão também pela apropriação da água. Este autor cita como exemplo a guerra entre Israel e os Palestinos que além da delimitação do território, das diferenças ocidente e oriente, das diferenças de religiosidade têm como motivo a apropriação das águas do Rio Jordão. (Chomsk,1996)

As guerras espetáculos televisivos, entre as quais a guerra pelo domínio das reservas petrolíferas que aparentemente são lutas do bem - do ocidente - contra o mal e os opressores - do oriente. Oculta-se a importância do espaço e da luta para obter suas reservas. Destaca Edward Said (Said,1990) que o ocidente inventou o oriente no processo de dominação histórico. Hoje é reinventado para continuidade do domínio das reservas petrolíferas.

Diz Edgar Morin que a violência é um câncer, produz metástases. O espetáculo midiático mostra a metástase mas não o câncer (Morin, 1996). A metástase da violência atinge a sociedade de forma generalizada desde as guerras pela apropriação das riquezas dos territórios até a violência cotidiana que aparece nos centros urbanos e que cada vez mais é dominada pelos que controlem as drogas, que antes, é claro, provocam a dependência das drogas.

É, de modo geral, a reflexividade do modo de produção capitalista, o câncer e sua metástase que provoca a destruição de homens (descartáveis - pois são em demasia, não se precisa de tantos para o mundo técnico), poluição, destruição das reservas da natureza.

\section{IV- Os deslocamentos de análises}

Há diversas formas de escamotear as relações sociais e o espaço. Destacamos os deslocamentos de análises como uma delas com o objetivo de destacar a importância da Geografia para o século XXI.

O fetiche das relações entre as coisas que oculta as relações entre os sujeitos cria uma série de deslocamentos nos discursos dominantes, que muitas vezes nos envolvem até pela necessidade de "reconhecimento" de nossa importância. Mas às vezes na procura de legitimidade com outras ciências, adotam-se os termos ou "noções" equivocadas. Há o perigo de manter subalternidade da Geografia e dos geógrafos por aceitar-se termos sem que - arcabouço teórico da Geografia esteja explicitado. Alertamos que trata-se aqui de alertar para a necessidade de análise crítica do ponto de vista da ciência geográfica e não de crítica. Alguns deslocamentos:

\section{O deslocamento do desenvolvimento para o desenvolvimento sustentável}

Desde a publicação do Relatório Nosso Futuro Comum em 1987 e principalmente após a Conferência das Nações Unidas para o Desenvolvimento e Meio Ambiente em 1992, tornou-se senso comum acrescentar o adjetivo sustentável : Desenvolvimento Sustentável, Agricultura Sustentável, Comércio Sustentável, Consumo Sustentável, regularização fundiária sustentável, educação ambiental sustentável, cidades saudáveis ou cidades sustentáveis e tantos outros.

Virou moda acrescentar-se a palavra sustentável. Mas a moda é o oposto da crítica, como nos ensina, Guy Debord (Debord, 1992)

O termo está institucionalizado porém ninguém sabe o que significa. Porque o termo é aceito? Partilho dos pensam que a institucionalização do termo saiu vitorioso pela hegemonia da economia neoclássica em especial nos órgãos de regulação e fomento de caráter mundial, como o FMI ou o Banco Mundial. 
Setenta anos da AGB: As transformações do espaço e a Geografia do Século XXI, Ocultação do Espaço e da Geografia pp. 21 - 33

Desenvolvimento Sustentável é uma das formas pelas quais o modo de produção que é insustentável busca legitimar-se cientificamente. O termo Desenvolvimento Sustentável tem mais de uma centena de definições onde sempre aparece que se deve cuidar do meio ambiente para as gerações presentes e futuras.

Em geral estes discursos que se pretendem científicos ocultam a reflexividade do sucesso do modo de produção. Entendo por Reflexividade, o sentido utilizado por Giddens (1997) não um reflexo mas uma autoconfrontação, em outras palavras, as contradições que podem ser analisadas com o método de análise do materialismo histórico.

A análise da dilapidação dos elementos da natureza não é nova, mas amplia-se com o conhecimento sobre as mazelas que o sucesso do modo de produção capitalista propicia. Para a Geografia, então, o tema remonta as suas origens, ou seja, não é novo.

O que é "novo" é o discurso sobre os problemas reais. Mas cabe ressaltar que há contradição entre os dois termos - o desenvolvimento não tem fronteiras, corresponde a uma energia para o futuro e o sustentável tem que estar no limite da sustentação. Que há contradições entre a fé cega na tecnologia e sua negação. A tecnologia resolverá os problemas no futuro mas ao mesmo tempo é negada pois se há preocupação com as gerações futuras significa que se conhece as mazelas do modo de produção e que a tecnologia não vai resolver os problemas no presente e nem no futuro. Que a insustentabilidade de mundo é visível pela pobreza e miséria das gerações presentes e pela dilapidação acelerada dos elementos da natureza. Desloca-se a responsabilidade para os que mal conseguem sobreviver e para o consumidor.

\section{Deslocamento do Desenvolvimento Sustentável para a Sustentabilidade}

Comunidades científicas sentindo-se incomodadas com a aceitação de um termo sem fundamentação mas que acham que tema e importante tentam operacionalizar o Desenvolvimento Sustentável com um novo termo Sustentabilidade. Procuram legitimarse migrando o Desenvolvimento Sustentável para sustentabilidade que também ninguém sabe o que é. Afirma-se que sustentabilidade, quando se trata da problemática ambiental é social, econômica, política, territorial, espacial.

As explanações sobre os sentidos da sustentabilidade esbarram em várias contradições:

a)Sustentabilidade social busca o desenvolvimento humano. É contraditória com a econômica.

b)Sustentabilidade econômica procura atribuir preço aos recursos naturais e avaliar os investimentos realizados na recomposição do meio natural degradado avaliado pelas contas.

c) Sustentabilidade política sustentabilidade social com ação política. Busca-se indicadores que possam mostrar esta ação como por exemplo: aumento do emprego, da escolaridade, do atendimento em equipamentos de doenças, do acesso aos equipamentos produzidos.

Utiliza-se para a sustentabilidade sóciopolíticas índices que permitam verificar melhoria de qualidade por exemplo o IDH - Índice de Desenvolvimento Humano. Contudo o IDH não expressa diretamente a problemática ambiental mas condições sócio-políticas.

d)Sustentabilidade territorial e espacial. O parâmetro é o de medições ecológicas, nas quais se destaca a capacidade de carga ou de suporte, pegada ecológica. Mas não se explica como medir a produção do espaço. O território é considerado como se não houvesse produção social. 
Várias questões se colocam, em especial para a Geografia, qual o território que será delimitado para analisar a sustentabilidade? Tem sido utilizado bacias hidrográficas. Os estudos em relação as bacias hidrográficas são tradicionais na geografia mas a tentativa de utilizar bacias como unidades de planejamento para a chamada gestão ambiental, coloca uma série de questões espaciais.

A natureza não tem fronteiras administrativas e assim a circulação do ar faz com que as chuvas ácidas ocorram longe da área mais poluída, o buraco da camada de ozônio mostra a circulação ascendente dos gases, o efeito estufa aquece a troposfera, a poluição dos rios provoca contaminação em toda a extensão à jusante, o uso de pesticidas na lavoura, os depósitos de poluentes, etc. provocam contaminação do solo.

Assim delimitar áreas para falar em sustentabilidade espacial, territorial ou ecológica é uma questão a ser aprofundada.

\section{Deslocamento da produção para o consumo}

Um dos desvios ou deslocamentos contemporâneos está relacionado ao fato de se privilegiar nas análises e nos discursos dominantes o consumo.

Um exemplo mais antigo está relacionado à época da produção da carteira hipotecaria dos IAPs, quando para alugar ou comprar uma casa era necessário estar ligado ao Instituto de Previdência correspondente à sua categoria de TrabalhoComércio, Indústria, Bancos. Etc. O que significava reconhecimento da CLT e das relações formais capitalistas de trabalho. Com a implementação do SFH- BNH (1964), a categoria trabalhador praticamente desapareceu e para ter acesso aos financiamentos para compra de casa utiliza-se classes de renda e não mais a relação de trabalho com carteira assinada. Um exemplo recente está relacionado ao fato de padrão de vida ser medido pela posse de bens de consumo ou aos equipamentos e meios de consumo coletivo. Neste caso verifica-se que não necessariamente a posse/ propriedade de bens de consumo significa melhoria de qualidade de vida. Pesquisa realizada com favelados no Rio de Janeiro, em 2001, por Janice Pearmam retomando contato com pesquisados em 1969 que deu origem ao livro o Mito da Marginalidade, mostra que os filhos dos favelados hoje tem mais acesso à bens de consumo (geladeiras, televisão, aparelho de som- que existiam em 1969 e a outros que se ampliaram: telefone fixo e celular, carro, computador. Mas tem maior instabilidade no emprego quando o conseguem(índice de desemprego é de $65 \%$ contra $31 \%$ de 1969), embora tenha diminuído em muito o analfabetismo e aumentado o grau de escolaridade (Pearman, 2002)

Um deslocamento mais atual diz respeito a idéia de consumo com a roupa de consumo sustentável. O aumento e a diversificação de produtos no mercado, que duram cada vez menos, a descartabilidade de embalagens e de produtos aumentam os resíduos, a poluição, etc. está sendo remetido para a responsabilidade dos "consumidores".

Afirmam os defensores do "consumo sustentável" que os consumidores devem ser conscientizados pela educação ambiental para verificar o que compram, devem andar de preferência de bicicleta, não devem jogar fora as embalagens dos produtos recicláveis, etc. O governador do Estado de São Paulo publicou, no início do mês de Julho de 2003 uma resolução para formar um grupo de estudos para "licitação" sustentável para garantir o consumo sustentável sem nenhuma explicação sobre o seu significado.

Assim, os discursos contra os desperdícios, contra a exploração, saem da esfera da produção para o consumo e para o consumo sustentável. É a moda que é o oposto da crítica.

Como a produção é ao mesmo tempo destruição e como se acelera com o avanço técnico que aumenta o sucesso do modo de produção o consumidor passam a ser responsabilizados pelas mazelas. Não há dúvidas que a contribuição de cada um é importante, mas esta é uma análise da ciência geográfica e não do comportamento individual. 


\section{Planejamento Urbano e seus deslocamentos}

O processo de urbanização acelerado, excludente, produz problemas que não se restringem às cidades mas é mais visível, em especial nos grandes centros urbanos.

Os problemas urbanos são produto do atuação das diferentes esferas do capital. Na ótica do desenvolvimento os problemas são atribuídos a desvios de modelos que tentam ser corrigidos pelo planejamento urbano ou urbanismo.

Têm como pressuposto a cidade ideal que não existe em nenhum lugar do mundo. Como diz Jane Jacobs é imprescindível criar uma ofensiva contra os princípios e os objetivos que moldam o planejamento urbano ortodoxo. (Jacobs, 2001).Com estes princípios constroem-se obras monumentais e as pessoas são estigmatizadas, expropriadas, desenraizadas, removidas como se fossem objetos.

O Planejamento neoliberal atinge sua expressão mais forte quando procura vender a imagem da cidade para os investidores, a moda de Barcelona, que é tida como o protótipo da Cidade ideal para atrair investimentos. Para isso utilizamse do chamado planejamento estratégico. Manuel Castels considera que a flexibilização da economia, globalização e complexidade da nova economia do mundo exigem o desenvolvimento do planejamento estratégico coerente e adaptativo para a nova estrutura de produção e administração. O objetivo deste planejamento coerente e adaptativo segue as regras do Banco Mundial que diz (1998): (in Vainer, 2000)

" Quando a liberação do mercado preside o desenvolvimento da economia global e a privatização, e os mercados financeiros se tornam rotinas, as cidades necessitam; Competir pelo investimento de capital, de tecnologia e competência gerencial; negócios;

Competir na atração de novas indústrias e

Ser competitiva no preço e na qualidade dos serviços;
Competir na atração de força de trabalho adequadamente qualificada"

Trata-se de um planejamento que considera a cidade como um organismo independente das relações sociais e das formas de apropriação e produção do urbano.

Concordo com Carlos Vainer, quando afirma que deve-se fazer um debate sério e rigoroso sobre este modelo de planejamento urbano com articulação de três analogias constitutivas: a cidade é uma mercadoria, a cidade é uma empresa a cidade é uma pátria. (Vainer, 2000) Em todas estas analogias as relações sociais estão ocultas.

Outras vertentes do planejamento tentam dizer que a cidade é ecossistema naturalizando as relações sociais e o planejamento consiste em minimizar os impactos ambientais e visam a cidade sustentável.

$\mathrm{Na}$ outra ponta, empregado por várias municipalidades é do planejamento participativo, outras palavra que virou moda.

Entre estas vertentes podemos citar a implantação do orçamento participativo e suas diversas variantes. Vários Geógrafos analisam este processo e chamam a atenção para a ausência do espaço nas propostas governamentais.

Mais recentemente para cumprir a determinação da Constituição de 1988 e do Estatuto da Cidade 2001, os governos municipais elaboram Planos Diretores, com presumida participação, para aplicação de instrumentos que garantam a função social da cidade.

Destaco que o Estatuto da Cidade mostra as contradições da apropriação e propriedade da terra urbana e reconhece a cidade real. Mas não suprime as contradições e conflitos.

\section{Deslocamento do Território dos Estados Nação para a Tecnosfera}

O avanço da tecnologia tem provocado uma "desterritoraliação" do Estado Nação em vários aspectos. 
Como já dito, na década de 80 , quando ficou patente a destruição das espécies animais e vegetais do planeta, além dos combustíveis fósseis e minérios, os países ricos apressaram-se em constituir bancos ex-situ para assegurarIhes o acesso e o poder sobre a sócio e a biodiversidade do planeta, não importando a região onde se dá a localização da espécie e em que país esta se situa.

Se em outro período histórico a divisão territorial do trabalho implicava em exportar diretamente matérias-primas como ferro, carvão, guano, etc, hoje a divisão territorial do trabalho implica na determinação dos potenciais genéticos ou de uso que serão guardados para a posteridade (guardados em bancos de germoplasmas e laboratórios). Os bancos exsitu, as patentes (em especial as intelectuais), visam a apropriação dos recursos dos territórios pela sua possibilidade futura.

As possibilidades da terapia gênica (genética), que avançam para a decodificação do genoma visando a melhoria da saúde, foram apropriadas pelo "Projeto de diversidade do Genoma humano" que tinha a ambição de coletar fragmentos do patrimônio genético dos povos em vias de desaparecimento (como os indígenas).

O Projeto de Diversidade do Genoma mostra a intenção da apropriação antecipada e não o valor em si. Tudo é para o futuro, para as gerações futuras?

As normas nacionais, impingidas pelas internacionais com relação às patentes, mostram que devemos ter afinco para estudar com profundidade e com rigor o poder da tecnoesfera que desterritorrializa o território dos estados-nação.

\section{A biotecnologia - o deslocamento da reprodução da vida?}

A revolução verde, como sabemos, provocou o aumento da produção, projetou maior importância à indústria química dominada pelas corporações multinacionais e ocasionou maior expansão dos experimentos. Não diminuiu a fome e a pobreza, ao contrário, trouxe aumento ao preço dos produtos agrícolas, propiciou mais contaminação dos solos e das águas, e tornou as espécies mais resistentes ás pragas agrícolas. No entanto o processo de novos produtos químicos continua a ser considerado como a "salvação da lavoura".

Os transgênicos, com as sementes terminater e trater, implicam no deslocamento do território que produzia as sementes das safras seguintes para a produção de sementes sintéticas realizadas nos laboratórios. A agricultura passa a depender cada vez mais da indústria e os agricultores dos laboratórios, e em especial, da indústria Monsanto. Não se sabe ainda as consequências para a saúde, mas já se verifica a dependência do agricultor. Não poderão mais reproduzir as sementes para uma outra safra e passam a depender da indústria monopolística para continuar com a sua produção. E, ao invés de utilizarem o conhecimento secular sobre a produção das sementes, necessitarão pagar royalties para a mesma produção.

O que significa, no espaço, esta alteração e este domínio de uma empresa multinacional ?

É preciso ressaltar que há resultados considerados positivos como a terapia gênica. E o que se fará no futuro quando a terapia gênica violar o código genético? Diz Frend Anderson, diretor de terapia gênica da Universidade da Califórnia do Sul, que "devese honrar o código profissional e antes de tudo pensar em não causar dano". ${ }^{1}$ Pode-se prever?

\section{V- A Geografia do Século XXI}

Apesar do aparente descrédito da Geografia, alguns importantes autores, entre os quais Boaventura Souza Santos e Edgar Morin, afirmam que a Geografia será uma ciência fundamental para analisar a complexidade do mundo atual, em especial considerando a "redescoberta" 
Setenta anos da AGB: As transformações do espaço e a Geografia do Século XXI,

Ocultação do Espaço e da Geografia pp. 21 - 33

do espaço que se dá pela intensificação dos problemas ambientais.

Edgar Morin, no livro a Inteligência da Complexidade (Morin, 2000) diz que:

a Geografia foi: "Marginalizada pelas disciplinas triunfantes, privada do pensamento organizador (que deveria ter ido além) do possibilismo de La Blache ou do determinismo de Ratzel, e das monografias verticais sobre uma região pela descrição dos estratos sucessivos físicos, biológicos e humanos (que todos sabemos dominaram os paradigmas da Geografia chamada de tradicional).

Afirma que "O progresso das ciências da terra e da ecologia revitaliza a geografia, ciência complexa por princípio, visto que ela cobre a física terrestre, a biosfera e as implantações humanas". "A geografia retoma suas perspectivas multidimensionais e globalizantes... A geografia se amplia na ciência da terra dos homens ".

Boaventura de Souza Santos, no livro A Crítica da Razão Indolente- contra o desperdício da experiência, Santos, 2000), instiga-nos a pensar sobre categorias de espaço quando propõe a análise sob a ótica do poder nas escalas e nos espaços: doméstico, da produção, do mercado, da comunidade, da cidadania e do mundial.

A Geografia adquire importância na visibilidade da crise dos paradigmas das ciências sociais e na descoberta da crise ambiental.

A revitalização da Geografia, a redescoberta do espaço, é a preocupação dos Geógrafos que têm analisado a produção e o consumo do espaço em todos os temas considerados relevantes, desvinculando-se do positivismo e colocando, com destaque, a fundamentação teórica que permite compreender as contradições e conflitos na e da produção do espaço.

O Espaço, exatamente por seu poder, ficou subjugado, nas análises, como decorrência do ideário do desenvolvimento, do progresso, que o modo de produção capitalista apregoava trazer para o mundo. E a Geografia ficou buscando o seu lugar no mundo em virtude de não mostrar a importância do espaço, seu objeto de estudo.
Por isso afirmamos que o nosso objeto de estudo é mais poderoso que a Geografia.

O Espaço sempre teve importância fundamental. O pensamento positivista, o conhecimento e a explanação fragmentada, procuravam esconder a importância do espaço, ocultando as relações sociais e o espaço.

Pela importância do nosso objeto de estudo temos que ter métodos de análise que permitam compreender a complexidade do espaço.

Foi nesse sentido que considerei importante demostrar o deslocamento dos discursos, pois eles podem continuar a ocultar a importância do espaço e da Geografia.

O capital, quando descobre que ficará em desvantagem com o esgotamento das reservas naturais, encontra palavras e termos que tentam fazer com que as análises sejam desviadas do real para o futuro. Penso que é importante analisar como se alteram os discursos com vista a manter a mesma essência em relação a exploração e espoliação do trabalhador com outras medidas. Porém lembro que a intensificação do avanço tecnológico que torna cada vez mais o trabalhador "desnecessário", não tem provocado "crises" para o capital. Busca-se, como já dito, alterar as regulamentação para torná-lo mais "livre". Em outras palavras, a crise da reprodução da vida não é considerada entrave à reprodução ampliada do capital. Mas a crise do ambiente é considerada problemática.

Considerando que o Espaço é a Terra dos Homens ou, melhor, que o espaço é produzido e reproduzido socialmente, a Geografia não pode excluí-la das análises. E devemos construir (ou reconstruir) um instrumental teórico adequado que possibilite à Geografia uma contribuição analítica para a o Século XXI.

Reafirmo que, constatado que o sucesso do modo de produção conecta-se diretamente à dilapidação e esgotamento dos recursos naturais, o Espaço ganha importância e as 
categorias analíticas da geografia são colocadas em destaque.

Dada a importância do espaço, nosso objeto de análise, nós, geógrafos, temos que compreender que não podemos mais ter complexo de inferioridade e nem aceitar a opressão ou aceitar, de forma subordinada, os desvios e deslocamentos de análises.

Precisamos perder o complexo de inferioridade que nos foi atribuído e que nós aceitamos e assumir a importância da Geografia para analisar o espaço. Não apenas as ciências triunfantes nos colocaram numa posição de subalternidade, mas nós mesmos, ao assumirmos as categorias de análises, os temas, os paradigmas de outras ciências, nos colocamos numa posição de inferioridade.

Há entre nós. geógrafos, um imaginário coletivo de "necessidade de reconhecimento" que parece depender do reconhecimento da importância do nosso objeto de estudo: o espaço.

Temos, na realidade, que mostrar que a importância do nosso objeto de estudo - o espaço- é fundamental para compreender o mundo do século XXI.

Hoje o que representa o espaço nos discursos? Penso ser uma questão, pois, se a essência não mudou, mudaram-se os discursos. Penso que esta é uma das questões para a Geografia do Século XXI.

Aparentemente é mais fácil cair no "canto da sereia" ao utilizar os deslocamentos dos discursos, a metodologia de análise de outras ciências, ou seja, colocarmo-nos à disposição de outras ciências, como se o espaço, nosso objeto de estudo, não fosse poderoso e não interferisse na vida cotidiana e na formulação dos paradigmas de outras ciências.

Mas só aparentemente é mais fácil, pois será cada vez mais difícil construir uma geografia comprometida com as transformações se cairmos no "canto da sereia" dos novos discursos que deslocam as análises.
Constitui, também, um grande desafio buscarmos a interação dos nossos conhecimentos com aqueles que aprofundam as análises da natureza e os que o fazem nas análises da sociedade. Ou seja, o reencontro das geografias.

Este reencontro não pode ser o mito do eterno retorno, mas deve nos auxiliar na busca do elo perdido para compreender a complexidade do mundo e a complexidade do nosso objeto de estudo: o espaço - a terra dos homens.

Retomando a necessidade de superação do positivismo, lembro que o símbolo da nossa bandeira é ordem e progesso (advindo da ciência positivista) e a descoberta de que é desordem (terceira lei da termodinâmica), e não a ordem, que provoca transformações. E cabe lembrar, também, que as máquinas não tem desordem, só tem a ordem definida pelos que as produziram e as programam.

São muitos, enfim, os desafios para pensar a Geografia no século XXI.

Usei uma perspectiva para análise. Há muitas outras. Utilizei, como referência, muitos estudos, análises, trabalhos e publicações, nem todos especificamente citados.

Encerro dizendo que compreender a importância da Geografia no Século XXI implica, também, no desafio da ação política se quisermos transformar o espaço. Desafio que não implica, apenas, em conhecer o espaço, mas fazer dele o nosso meio de luta.

Eu agradeço, novamente, a honra que me foi concedida para ministrar a Conferência de Abertura do VI Congresso Brasileiro da AGB porque, para além de toda a emoção permitiume pensar sobre alguns desafios : de como o sucesso do modo de produção traveste-se freqüentemente para ocultar as relações sociais; de como a Geografia será uma ciência poderosa se analisar a complexidade do espaço com teoria e metodologia adequadas; de que o espaço é mais poderoso do que a Geografia pois transformou-se, mesmo quando os geógrafos não deram conta de analisar a complexidade do espaço. 


\section{Notas}

1 -Conferência de abertura no VI Congresso de Geógrafos - AGB- Goiânia - julho de 2004.
2 - Notícias de jornais do período.

\section{Bibliografia}

Chauí, Marilena, - Artigo - Caderno Mais -Folha de São Paulo 20/06/04- 2004. Brasil - Mito fundador e sociedade autoritária - Fundação Perseu Abramo-2000

Chomsky, Noam- Novas e Velhas Ordens Mundiais - Editora Página Aberta-SP- 1996

Debord, Guy - La Société du spectacle Gallimard - Paris -1992

Giddens, A.; Beck, U.; Lash, S.; Modernização Reflexiva - Editora da Unesp- São Paulo-1997

Harvey, David A Condição Pós-Moderna Edições Loyola -1992

Jacobs, Jane- Morte e Vida nas Grandes Cidades - Editora Martins Fontes - São Paulo- 2001

Morin, E. e Moigne, Jean-Louis A inteligência da Complexidade - Editora Fundação Petrópolis Rio de Janeiro. 2000

Morin, Edgar. Ciência com Consciência - Editora Bertrand Brasil - Rio de Janeiro 1996 -

Pearman, Janice -Informações de Pesquisa Jornal Folha de São Paulo-2002
Rybczynski, W. Vida nas Cidades - expectativas urbanas no nodo mundo - Editora Record - São Paulo -1996

Said, Edward Orientalismo - O Oriente como invenção do Ocidente - Editora Cia. Das LetrasSão Paulo -1990

Santos, Boaventura Sousa -A critica da razão indolente Contra o desperdício da experiência - Editora Cortez - São Paulo 2000

Santos, Laymert Garcia dos - Politizar as novas tecnologias Editora 34 - São Paulo- 2003

Santos, Milton- A Natureza do Espaço-Técnica e Tempo- Razão e Emoção- Editora Hucitec1996

Vainer, C. Pátria, Empresa e Mercadoria - in A cidade do Pensamento Único - Org.Otilia Arantes, Carlos Vainer e Ermínia Maricato Editora Vozes - São Paulo -2000

Virilio, Paul -- A Arte do Motor - Estação Liberdade- São Paulo -1996 
